\title{
Atrial septal aneurysm as a cause of abnormal left atrial flow: An echocardiographic study
}

\author{
DONALD J. SOUCIER, DO \\ FRANK CORBALLY, DO
}

Atrial septal aneurysms, although rare, are being found with an ever increasing frequency through the technology of two-dimensional echocardiography. In this article, we report the identification of an atrial septal aneurysm and abnormal systolic flow toward the transducer and mitral valve by use of two-dimensional echocardiography with pulsed-wave Doppler capability.

(Key words: Atrial septal aneurysm, cardiac, defect, malformation, cardiovascular abnormality, echocardiography)

An atrial septal aneurysm is a thin, localized protrusion of the interatrial septum in the region of the fossa ovalis. ${ }^{1}$ It occurs at an incidence of 0.2 to 1 per 100 population. ${ }^{1,2}$ The protrusion is often fenestrated ${ }^{2,3}$ and can appear as a primary defect (ie, not associated with congenital heart disease) or a secondary defect (ie, associated with congenital heart disease and the presence of a significant pressure gradient between the two atria). An atrial septal aneurysm is present and defined when there is a bulging of the interatrial septum protruding more than $6 \mathrm{~mm}$ into the right or left atrium (or both) during the cardiac cycle. ${ }^{4}$

It has been postulated that an atrial septal aneurysm is caused by a congenital disorder of connective tissue. The aneurysm is absent in childhood, the malformation becoming apparent over time. The fossa ovalis membrane and the mitral, tricuspid, aortic, and pulmonic apparatus are composed of endocardial tis-

From the Department of Cardiology, University of Medicine and Dentistry of New Jersey-School of Osteopathic Medicine, where, at the time this article was written, Dr Soucier was a cardiology fellow, and Dr Corbally was assistant clinical professor of medicine. Dr Soucier is presently with the Public Health Service in Ivor, Va.

Reprint requests to Frank Corbally, DO, 108 Foxshire Dr, Lancaster, PA 17601. sue, and an inherent deficiency that occurs in one might be expected to occur in the others. ${ }^{5}$ An atrial septal aneurysm has been associated with multiple cardiovascular abnormalities (Table). ${ }^{1-4,6-12}$ Most atrial septal aneurysms are thought to be clinically silent, and they are detected only incidentally. ${ }^{1-4}$

\section{Report of case}

A 39-year-old woman was evaluated in the echocardiography laboratory because of a complaint of palpitations for the previous 9 months. Her symptoms were exacerbated by caffeine, anxiety, and, occasionally, activity. Her medical and surgical histories were unremarkable. She did not smoke. Her physician had prescribed propranolol hydrochloride on an as-needed basis for palpitations. Results of her physical examination were essentially normal.

The patient's electrocardiogram demonstrated a normal sinus rhythm, incomplete right bundlebranch block, anterior axis rotation, and nonspecific ST-T-wave changes. On the chest roentgenogram, the lung fields and the cardiac silhouette appeared to be within normal limits.

A two-dimensional echocardiogram and Doppler test were performed with a commercially available echocardiograph (Hewlitt Packard, Andover, Mass; model $77020 \mathrm{AC}$ ) and a $2.5-\mathrm{MHz}$ phased-array transducer system with pulsed-wave Doppler capability. This study demonstrated normal chamber size. There was moderate thickening of the anterior mitral leaflet with prolapse and an atrial septal aneurysm involving the entire septum. The aneurysm protruded into the left atrium approximately $1.1 \mathrm{~cm}$ during middle-to-late systole and into the right atrium approximately $1.2 \mathrm{~cm}$ during early-to-middle diastole (Figs 1 and 2). This motion, in association with a normal right and left atrial presssure gradient, was described by Roberts. ${ }^{6}$ Technical difficulties made it impossible to assess changes in atrial septal motion during inspiration in our patient.

Contrast echocardiography was performed by use of preserved saline solution. The microcavitations 
Table

Associated Cardiovascular and Systemic Abnormalities

\begin{tabular}{|c|c|c|}
\hline Abnormality & $\begin{array}{l}\text { Incidence of patients } \\
\text { with associated } \\
\text { atrial septal defect }\end{array}$ & Reference(s) \\
\hline \multicolumn{3}{|l|}{ Embolic phenomena: } \\
\hline Cerebrovascular accidents & Up to $28 \%$ & $1,3,4$ \\
\hline Pulmonary embolism & Unknown & \\
\hline Transient ischemic attacks & Up to $25 \%$ & 8 \\
\hline Mitral valve prolapse & Up to $48 \%$ & $2,9,10$ \\
\hline Tricuspid valve prolapse & Unknown & 2,9 \\
\hline Atrial septal defect & Up to $30 \%$ & 4 \\
\hline Arrhythmias/palpitations & Unknown & 11 \\
\hline $\begin{array}{l}\text { Mitral, tricuspid, and } \\
\text { pulmonary venous obstruction }\end{array}$ & Unknown & 7,10 \\
\hline Coronary artery disease & Unknown & 10 \\
\hline Cardiomyopathies & Unknown & 10 \\
\hline Systemic hypertension & Unknown & 10 \\
\hline Aortic stenosis & Unknown & 7 \\
\hline Congenital heart disease & Unknown & 2 \\
\hline Marfan's syndrome & Unknown & 12 \\
\hline
\end{tabular}

failed to demonstrate right-to-left or left-to-right shunting by either direct crossover of the microbubbles or negative contrast effect seen with left-toright shunting. Results of Doppler examination of the atrial septum in the subcostal and apical fourchamber views failed to demonstrate any evidence of right-to-left or left-to-right shunting. This is in contradistinction to the findings of a study by Belkin and associates, ${ }^{3}$ who observed that all 13 of their patients with an atrial septal aneurysm had evidence of right-to-left shunting at the atrial level.

The pulsed-wave Doppler signal positioned in the middle aspect of the left atrium demonstrated abnormal flow in systole toward the transducer and mitral valve (Fig 3 ). To our knowledge, this abnormality has not been described before.

\section{Discussion}

An atrial septal aneurysm can be classified into any one of three major groups, as described by Hanley and associates, ${ }^{15}$ depending on the amount of the atrial septum involved and on the maximal extent of phasic oscillations of the aneurysmal membrane during the cardiorespiratory cycle. Type 1 atrial septal aneurysm involves the fossa ovalis with maximal oscillations occurring toward the right atrium. Type 2 atrial septal aneurysm involves the fossa ovalis, with maximal oscillations occurring toward the left atrium. Type 3 atrial septal aneurysm, the category to which our patient's aneurysm belongs, involves the entire atrial septum. This defeci has been observed previously ${ }^{7}$ in patients with complex congenital malformations of the hypoplastic right ventricular type, all of whom had associated atrial septal defects. Our patient had neither a hypoplastic right ventricle nor an atrial septal defect.

The atrial septal motion, as described in our case presentation, has been described previously and was found to be associated with normal atrial pressure gradients. ${ }^{5}$ The leftward 

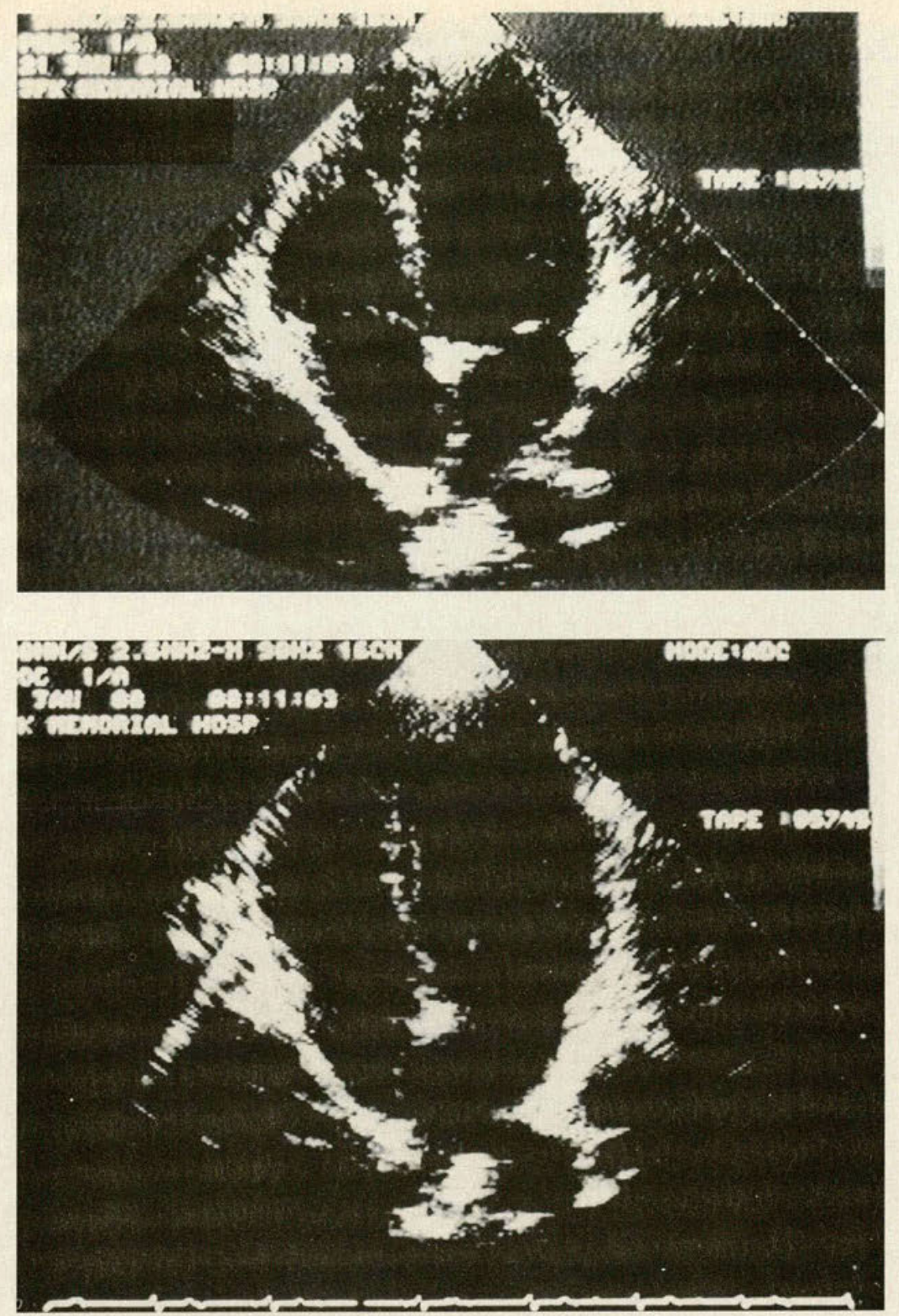

Figure 1. Apical four chamber view of the heart in early diastole.

Figure 2. Apical four chamber view of the heart in mid-diastole. motion of the interatrial septum in systole was postulated to occur because left atrial systole ends before right atrial systole. This pattern is consistent with the normal physiologic variations of blood flow to the atrium. ${ }^{8}$ The findings noted with pulsed-wave Doppler examination can be explained by the fact that the movement of the atrial septum toward the left atrium in systole sets up turbulent flow (eddy currents) toward the transducer and mitral valve.

\section{Conclusion}

An atrial septal aneurysm is a rare localized phenomenon of the interatrial septum in the region of the fossa ovalis. It is a disorder of connective tissue ${ }^{4}$ and may be associated with other endocardiac defects. It can be associated with multiple clinical presentations and should always be considered in their differential diagnosis. In the case described, a 39-year-old woman had an atrial septal aneurysm that in- 


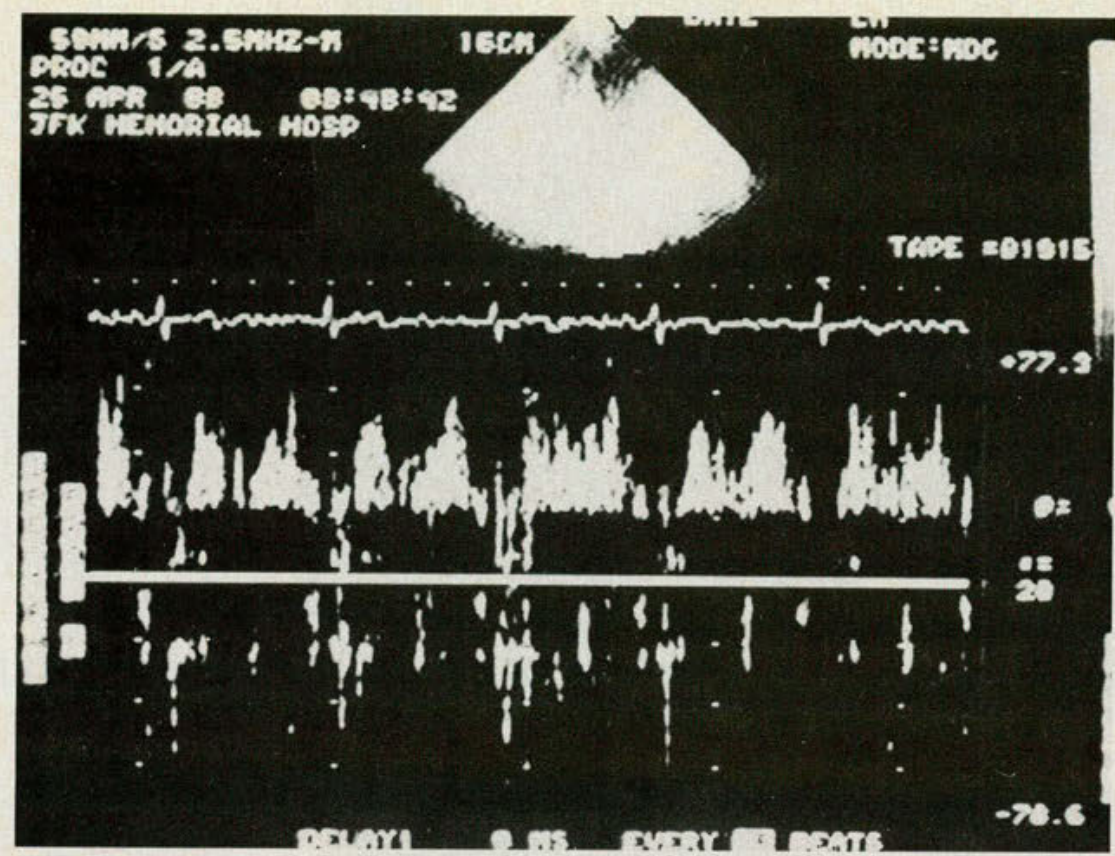

Figure 3. Pulsed-wave Doppler signal demonstrating abnormal systolic flow.

volved the entire septum without evidence of an atrial septal defect or a hypoplastic right ventricle. At the time this article was written, the abnormal systolic flow demonstrated in the left atrium with pulsed-wave Doppler had not been previously reported.

\footnotetext{
1. Shenoy MM, Vijoykumar PM, Friedman SA, et al: Atrial sep tal aneurysm associated with systemic embolism and interatrial right to left shunt. Arch Intern Med 1987;147:605-606.

2. Bewick DJ, Montague TJ: Atrial septal aneurysm: Spectrum of clinical and echocardiographic presentations. Can Med As. soc $J$ 1987; 136:609-611.
}

3. Belkin RN, Hurwitz BJ, Kisslo, J: Atrial septal aneurysm: Association with cerebrovascular and peripheral embolic events. Stroke 1987;18:856-862

4. Gallet B, Malerque MC, Adams C, et al: Atrial septal aneurysm: A potential cause of systemic embolism. An echocardiographic study. Br Heart $J$ 1985;53:292-297.

5. Gondi B, Nanda NC: Two-dimensional echocardiographic features of atrial septal aneurysms. Circulation 1981;63:452-457.

6. Roberts WC: Aneurysm (redundancy) of the atrial septum, ovale membrane, and prolapse (redundancy) of the mitral valve. C Fossa 1984;54:1153-1154.

7. Huet Y, Menu P, Geschwind H, et al: Right atrial septal aneurysm: An unusual cause of recurrent pulmonary embolism. Crit Care Med 1985;13:510-515
8. Roydant R, Chague F, Dehant P, et al: Les aneurysms en septum interauriculaire: Du diagnostic á la thérapeutique: Àpropos de 33 cas consécutifs. Arch Mal Coeur 1987;80:1117-1124. 9. Iliceto S, Papa A, Sorino M, et al: Combined atrial septal aneurysm and mitral valve prolapse: Detection by two-dimensional echocardiography. Am J Cardiol 1984;54:1151-1153.

10. Longhini C, Brunazzi MC, Musacci G, et al: Atrial septal aneurysm: Echopolycardiographic study. Am J Cardiol 1985;56:653-656.

11. Iliceto S, Antonelli G, Chiddo A, et al: Two-dimensional echocardiographic recognition of an atrial septal aneurysm. Int $J$ Cardiol 1983;2:447-449.

12. Magherini A, Margioha C, Bandini F, et al: Atrial septal aneurysm: Spectrum of clinical and echocardiographic presentations. Can Med Assoc J 1987;58:172-173.

13. Vandenbossche JL, Englert M: Effects of respiration on an atrial septal aneurysm of the fossa ovale shown by echocardiographic study. Am Heart $J$ 1982;103:922-923.

14. Belkin RN, Waugh RA, Kosslo J: Interatrial shunting in atrial septal aneurysm. Am J Cardiol 1986;57:310-312.

15. Hanley PC, Tajik AJ, Hyres JK, et al: Diagnosis and classification of atrial septal aneurysm by two-dimensional echocardiography: Report of 80 consecutive cases. $J$ Am Coll Cardiol 1985;6:1370-1382

16. Alexander MD, Bloom KR, Hert $P$, et al: Atrial septal aneurysm: A cause for midsystolic click: Report of a case and review of the literature. Circulation 1981;63:1186-1188.

17. Sahn DJ, Allen HP, Anderson R, et al: Echocardiographic diagnosis of atrial septal aneurysm in an infant with hypoplastic right heart syndrome. Chest 1978;73:227-230. 


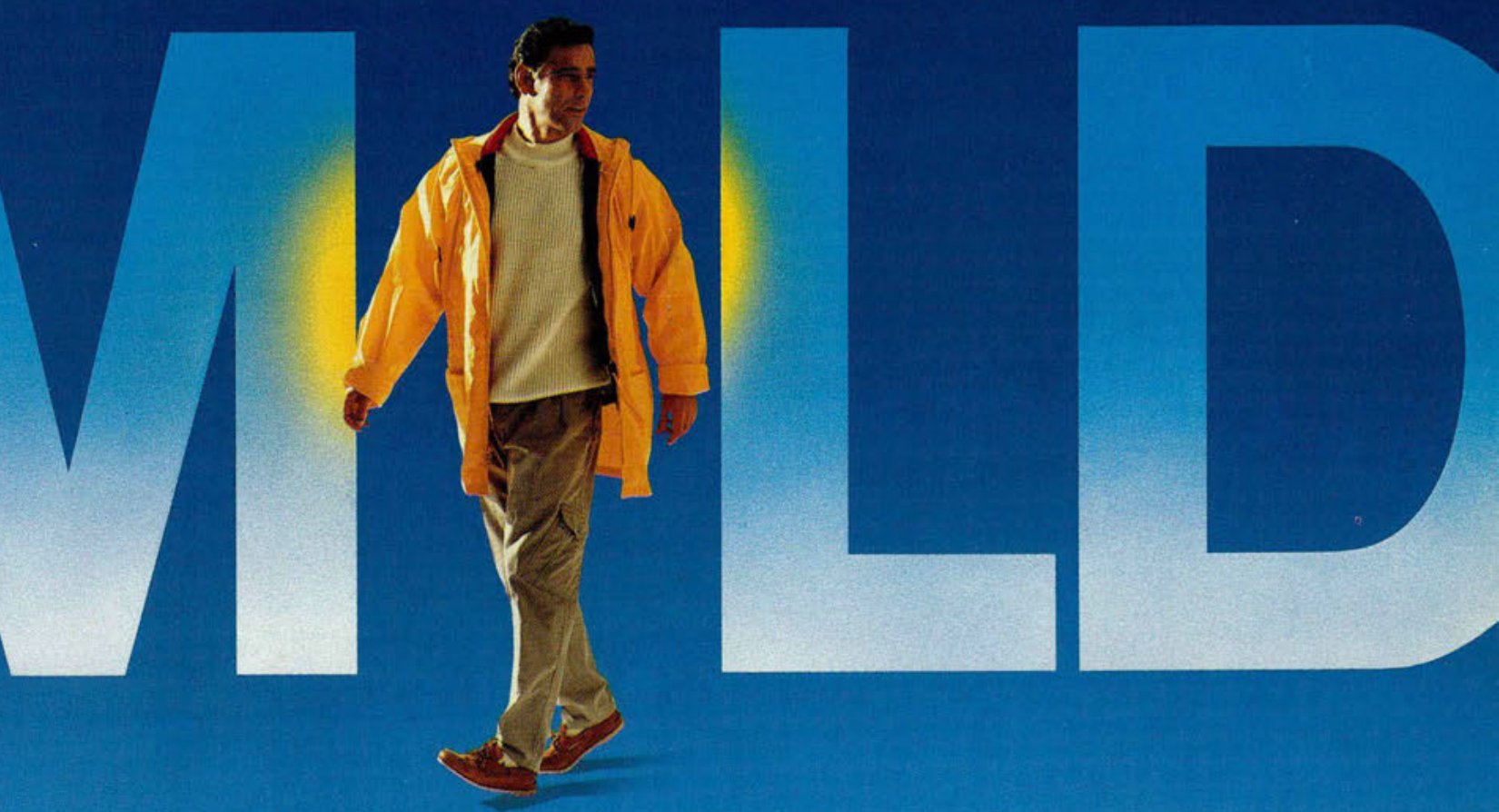

\title{
FEELING GOOD WITH MILD HYPERTENSION
}

\author{
- HIGH SINGLEAGENT EFFICACY ${ }^{\dagger}$ \\ - LOW INCIDENCE OF SIDE EFFECTS" \\ - UNIMPAIRED QUALITY OF LIFE \\ SHOWN IN THREE CLINICALSTUDIES ${ }^{24}$
}

- As determined in clinical studies with dosages titrated up to 360 or 480 mg daily Total daily dosages above $240 \mathrm{mg}$ wereand should be administered in divider doses. Calan SR should beadministered with food. iconstipation, which is easily managed in most patients is the most commonly reported side effect of Calan SR. Please see next page of this advertisement for references and a brief summary of prescribing information.
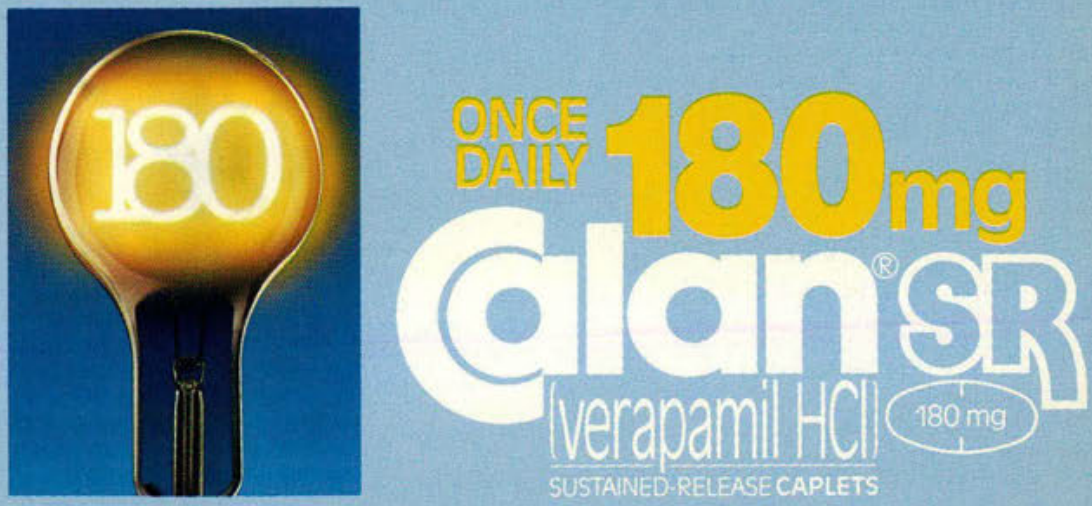



\section{A BRIGHT IDEA TOSTAY WITH IN MILD HYPERTENSION}

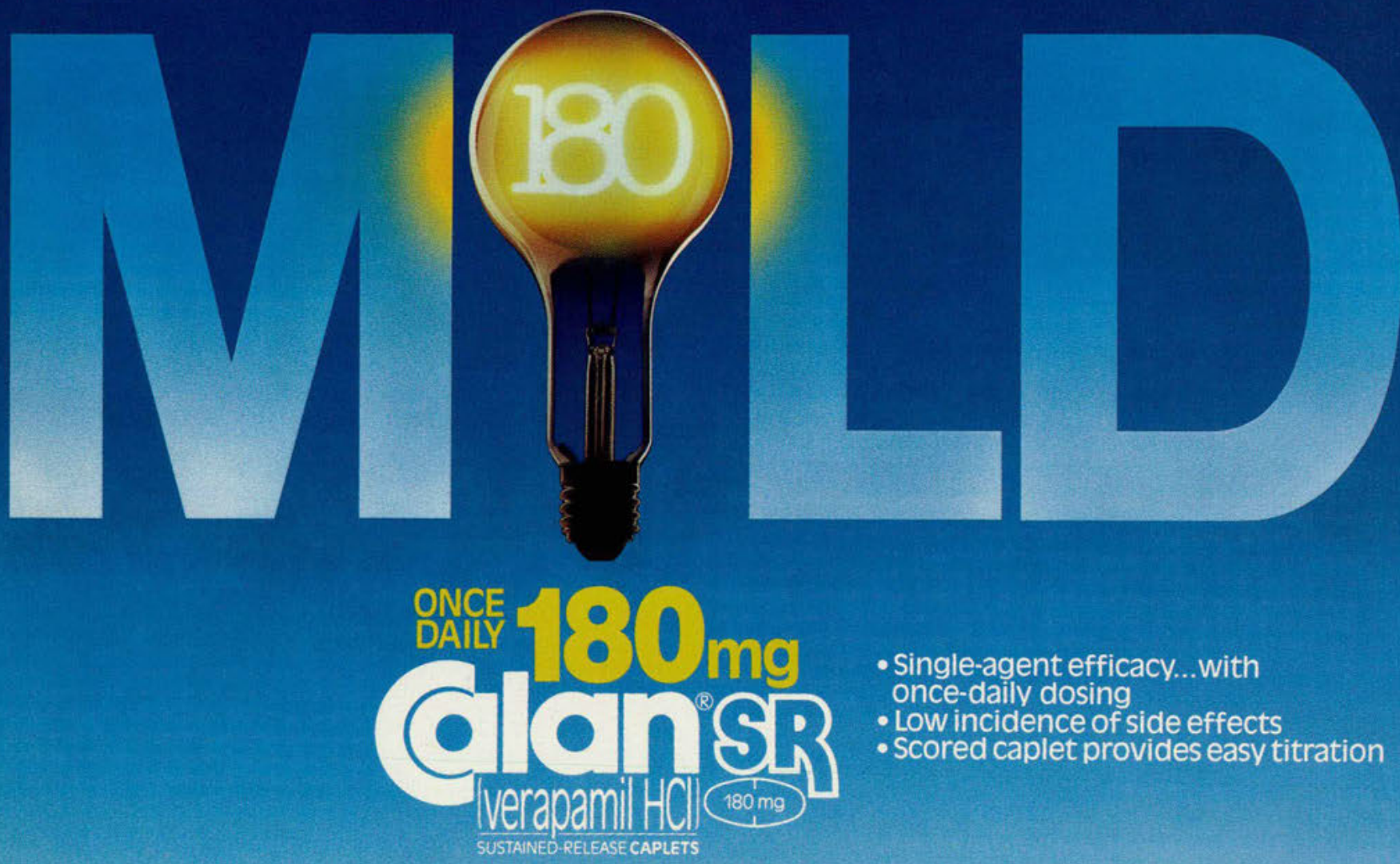

References:

1. Data on file, GD. Searle \& CO. 2. Paimer A. Fletcher A. Hamilton C, et al A comparison of verapamil and nifedipine on quality of life. Br J Clin Pharmacol 1990:30:365-370. 3. Fletcher AE Chester PC, Hawkins CMA et al: The effects of verapamil and propano Iol on quality of life in hypertension. J Hum Hypertens 1989,3.125-130.4. CroogSH, Kong BW, LevineS, et al: Hypertensive black men and women: Quality of life and effects of antihypertensive medications. Arch intern Med 1990:150:1733-1741

\section{Calan SR 180-mg caplets are scored for easy titration.}

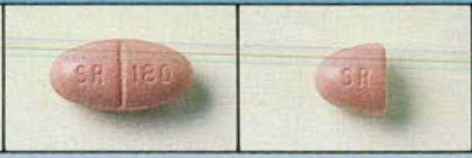

lowering agents. Disopyramide should not be given within 48 hours before or 24 hours after verapamil administration. Concomitant use of flecainide and verapamil may have additive effects on myocardial contractility, AV conduction, and repolarization. Combined verapamil and quinidine therapy in patients with hypertrophic cardiomyopathy should be avoided, since significant hypotension may result. Concomitant use of lithium and verapamil may result in a lowering of serum lithium levels or increased sensitivity to lithium. Patients receiving both drugs must be monitored carefully. Verapamil may increase carbamazepine concentrations during combined use. Rifampin may reduce verapamil bioavailability. Phenobarbital may increase verapamil clearance. Verapamil may increase serum levels of cyclosporin. Concomitant use of inhalation anesthetics and calcium antagonists needs careful titration to avoid excessive cardiovascular depression. Verapamil may potentiate the activity of neuromuscular blocking agents (curarelike and depolarizing); dosage reduction may be required. Adequate animal carcinogenicity studies have not been performed. One study in rats did not suggest a tumorigenic potential, and verapamil was not mutagenic in the Ames test. Pregnancy Category $C$. There are no adequate and well-controlled studies in pregnant women. This drug should be used during pregnancy, labor, and delivery only if clearly needed. Verapamil is excreted in breast milk: therefore, nursing should be discontinued during verapamil use.

Adverse Reactions: Constipation (7.3\%), dizziness (3.3\%), nausea (2.7\%), hypotension $(2.5 \%)$, headache $(2.2 \%)$, edema $(1.9 \%)$, CHF, pulmonary edema $(1.8 \%)$, fatigue $(1.7 \%)$, dyspnea $(1.4 \%)$, bradycardia: $\operatorname{HR}<50 / \mathrm{min}(1.4 \%)$, AV block: total $1^{\circ}, 2^{\circ}, 3^{\circ}(1.2 \%), 2^{\circ}$ and $3^{\circ}(0.8 \%)$, rash $(1.2 \%)$, flushing $(0.6 \%)$, elevated liver enzymes. The following reactions, reported in $1.0 \%$ or less of patients, occurred under conditions where a causal relationship is uncertain: angina pectoris, atrioventricular dissociation, chest pain, claudication, myocardial infarction, palpita tions, purpura (vasculitis), syncope, diarrhea, dry mouth, gastrointestinal distress, gingival hyperplasia, ecchymosis or bruising, cerebrovascular accident, confusion, equilibrium disorders, insomnia, muscle cramps, paresthesia, psychotic symptoms, shakiness, somnolence, arthralgia and rash, exanthema, hair loss, hyperkeratosis, macules, sweating, urticaria, Stevens-Johnson syndrome, erythema multiforme, blurred vision, gynecomastia, increased urination, spotty menstruation, impotence.

$12 / 21 / 89 \cdot P 90-W 198 \mathrm{~V}$

Address medical inquiries to

G.D. Searle \& Co.

Medical \& Scientific

4901 Searle Parkway

Skokie, II 60077

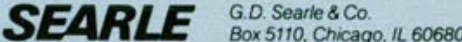



